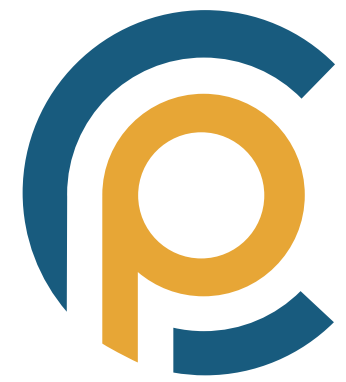

\title{
La Alfabetización. Una competencia educativa para el mundo globalizado
}

\author{
Literacy. An educational competence \\ for the globalized world
}

Recibido: 10/08/2020 | Revisado: 15/10/2020 | Aceptado: 19/10/2020 | Publicado: 22/12/2020

\section{Joel Oswaldo Vielma Rondón}

Universidad de Los Andes (Venezuela)

joelvielma.15@gmail.com

https://orcid.org/0000-0001-8906-8930

\begin{abstract}
Resumen: En este artículo se pretende reflexionar sobre las implicaciones de la alfabetización como una competencia educativa fundamental para los ciudadanos del mundo globalizado. A fin de lograr tal propósito, se caracterizan algunos de los senderos sobre los cuales se disemina este saber y se explica cómo se relaciona con la cultura escrita, los procesos educativos y las Tecnologías de la Información y la Comunicación (TIC). Además, se abre un espacio para la reflexión sobre lo relativo a este tema en la Venezuela de los últimos años; se apoya esta discusión en la revisión de datos oficiales, realizada por Bravo (2011) y Uzcátegui y Bravo (2017). Se insiste en que la alfabetización se vincula de manera determinante con la construcción de la autonomía personal necesaria para aprender a lo largo de la vida y la consideración de la lectura y la escritura como prácticas sociales y culturales. Para concluir, se estima que el compromiso con la alfabetización y el fomento de la cultura escrita, en sus diferentes formatos y modalidades, debe ser asumido por todas las entidades y todos los actores sociales. Se subraya, en este caso, la responsabilidad que tienen los gobiernos democráticos al desplegar políticas culturales, educativas, sociales y económicas, pues estas acciones aumentan su responsabilidad con la gente, y también, con sus condiciones de vida.
\end{abstract}

Palabras clave: Alfabetización, aprendizaje, ciudadanía, educación, tecnología.

\begin{abstract}
This article seeks to reflect on the implications of literacy as a fundamental educational competence for citizens of the globalized world. In order to achieve this purpose, we characterize some of the paths on which this knowledge is disseminated and explain how it relates to written culture, educational processes and Information and Communication Technologies (ICT). In addition, it opens a space for reflection on the matter in Venezuela in recent years; supported by Bravo (2011) and Uzcátegui and Bravo (2017) reviews of official data. It is emphasized that literacy is decisively linked to the construction of the personal autonomy necessary for lifelong learning and the consideration of reading and writing as social and cultural practices. In conclusion, it is considered that all entities and social actors should assume the commitment to literacy and the promotion of written culture, in its different formats and modalities. In this case, democratic governments' responsibility of implementing cultural, educational, social and economic policies is underlined, for their implementation increases responsibility towards the people, and also, towards their living conditions.
\end{abstract}

Keywords: Literacy, learning, citizenship, education, technology. 
El contenido social que subyace al hecho educativo lo configura como un símbolo de desarrollo y progreso, razón por la que se le otorga un papel central en las políticas públicas de casi todos los países del mundo. Es innegable el avance social y económico de muchas naciones gracias a que la educación se posiciona en el centro de las preocupaciones y las iniciativas gubernamentales. Sin embargo, es necesario decir, que en su nombre se cometen innumerables injusticias que acrecientan las desigualdades y extienden la pobreza en el tiempo.

Precisamente, la alfabetización es uno de esos temas educativos aún no resueltos, lo que influye de manera crucial en el mantenimiento de la inequidad y el limitado acceso a las oportunidades académicas y laborales que tienen las personas en condición de pobreza. Uzcátegui y Bravo (2017), señalan que "la alfabetización es un problema social y pedagógico que debe enfrentar las sociedades que han suscrito la escolarización masiva de la población" (p. 33). Es preocupante que aún se observe la falta de comprensión acerca de cómo la lectura y la escritura se pueden convertir en herramientas para el empoderamiento y el crecimiento humano, dado que permiten el despertar de la conciencia y la formación del pensamiento crítico. Asimismo, favorecen la interacción y el establecimiento de relaciones humanas en distintos niveles y en múltiples ámbitos de participación.

A lo largo de este trabajo, realizado desde una orientación teórica, documental y crítica, se pretende reflexionar sobre las implicancias de la alfabetización al considerarla como una competencia educativa esencial para conseguir el pleno desarrollo de las sociedades del mundo globalizado, con posibilidades para impulsar el cambio y el progreso económico y social, además de enaltecer la condición humana. Para alcanzar dicho propósito, se caracterizan algunos de los senderos sobre los cuales se disemina este saber y se explica cómo relaciona con la cultura escrita, los procesos educativos formales y las Tecnologías de la Información y la Comunicación (TIC). Se analiza quién o quiénes son los responsables de fomentar la alfabetización y la cultura escrita, en sus múltiples formatos y manifestaciones. Aunado a ello, se aborda de manera particular, el tratamiento que se le ha dado a este asunto en Venezuela durante las dos primeras décadas del nuevo mileno (Bravo, 2011; Uzcátegui y Bravo, 2017).

Se insiste en que el dominio de la lectura y la escritura, así como su uso cotidiano, dentro y fuera de los espacios educativos, se vinculan de manera determinante con las experiencias ciudadanas. Tal y como expone Águila (2019), en dichas experiencias "están presentes los valores, actitudes y modos de ser propios de una democracia" (p. 72). Es por esta razón, que la cultura escrita, en sus diversas prácticas y expresiones, debería fortalecerse, sobre todo, en aquellas naciones que se precian de su pluralismo y demás principios democráticos.

\section{La alfabetización}

Tradicionalmente, la alfabetización se ha asociado con la escuela primaria, se asume que es allí donde los niños adquieren este conocimiento y que, una vez consolidado el proceso de alfabetización inicial, ellos están preparados para seguir leyendo y escribiendo por su cuenta. A estas consideraciones, subyace una concepción restringida de la alfabetización, ya que como analiza Torres (2008) se ve reducida a la capacidad que se puede alcanzar para codificar y descodificar textos.

Si bien, el proceso de alfabetización inicial se convierte en la base de todos los aprendizajes a lo largo de la vida, este no es un conocimiento suficiente para resolver todas las situaciones sociales implicadas en la cotidianidad. Además, deviene en un saber insuficiente para actuar en los diferentes contextos de acción social y cultural a los que se tienen que enfrentar los ciudadanos en pleno cumplimiento de sus deberes y derechos democráticos.

Concebida desde un sentido amplio, la alfabetización supera las condiciones de una actividad que pueda declararse en algún momento como absolutamente terminada. Por el contrario, es un proceso que se manifiesta en permanente construcción y que involucra el manejo de variadas competencias en lectura y escritura. Dichas competencias, van desde el dominio mecánico del sistema alfabético 
para codificar (escribir) y descodificar (leer) textos, hasta la producción y comprensión de discursos que cumplen funciones sociales, académicas y culturales específicas. Al respecto, Torres (2008) afirma que "Una persona está alfabetizada cuando maneja con autonomía el lenguaje escrito, lee comprendiendo lo que lee y es capaz de transmitir con claridad sus propias ideas por escrito, de modo que otras personas pueden comprender lo que escribe" (p. 1).

De ahí, que se torna prudente plantear ahora las siguientes interrogantes: ¿Hacen todos los ciudadanos un uso igualitario de los procesos de la lectura y la escritura?, ¿qué implicancias tiene para una persona alfabetizarse?, ¿qué importancia tienen las políticas públicas en cuanto a alfabetización y cultura escrita para el progreso y el bienestar socioeconómico de los países?

La alfabetización comporta un amplio conocimiento del lenguaje, expresado en textos, imágenes, signos, símbolos y códigos dispuestos en formatos analógicos o electrónicos. Al mismo tiempo, incluye la capacidad de hacer abstracciones, predicciones y transposiciones de lo leído o escrito, según el contexto o la situación comunicativa particular. Lipman (2016) manifiesta que el derecho a la alfabetización de la niñez no puede reducirse a conseguir una habilidad aceptable de lectura y de escritura, sino que se debe llegar a los niveles superiores de la aceptabilidad: razonabilidad, capacidad de juicio, inventiva y capacidad para apreciar. En lugar de ello, se establecen estándares mínimos relacionados con la pertinencia y consistencia, obviando otros más elevados que le permitirían al alumnado dar una mejor respuesta a las exigencias actuales de la vida en común.

En atención a lo anterior, es posible afirmar que las universidades deben contribuir en la tarea de optimizar las condiciones y la calidad de los procesos de alfabetización, a través de la formación de docentes que posean una sólida formación conceptual en torno a la enseñanza de la lengua. Sin duda, se necesita que las situaciones de enseñanza sean desarrolladas en un marco pedagógico caracterizado por su calidad operativa y organizativa. Experiencias de campo como la de Flores y Sánchez (2013) con estudiantes de pedagogía que llevan a cabo tareas de alfabetización con adultos "analfabetos", o la de Vielma (2016), haciendo promoción de la lectura en un entorno educativo rural, ayudan al enriquecimiento de la identidad profesional. Dichas investigaciones, invitan a los docentes a mirarse a sí mismos como agentes que estimulan e impulsan cambios en el entorno comunitario, y que valoran el lenguaje escrito como un bien cultural que debe estar al alcance de todas las personas, independientemente del lugar donde se encuentren, su edad u oficio.

Ahora bien, es preciso destacar que la calidad no puede ser solo un rasgo distintivo del perfil del docente que se forma o se especializa en las facultades y escuelas de educación, para atender estudiantes en las aulas de los primeros grados, sino también de las campañas, planes y macro proyectos de carácter oficial, diseñados con la intención de alfabetizar poblaciones vulnerables. Se hace referencia en este caso, a los programas financiados por los gobiernos y que se orientan a acercar la lengua escrita a la gente más desfavorecida, con niveles de formación deficientes y de grupos etarios diversos. Para el despliegue de estas iniciativas, se requiere de una clara conciencia política, ética y moral de parte de los gobiernos, y quizá también, en un modo distinto, de los destinatarios, acerca del valor de la alfabetización como un factor indispensable para el desarrollo integral de las sociedades.

Torres (2008) describe algunos de los principales programas de alfabetización de adultos en países como Ecuador, Cuba y Venezuela. Sus reflexiones clarifican la responsabilidad de las autoridades gubernamentales en la planificación, ejecución, evaluación y seguimiento de los programas de alfabetización. Expone el uso político electoral de las campañas de alfabetización, presentadas en estos países como medidas "salvadoras" para remediar la pobreza y la inequidad todavía existentes. Advierte, que es un exceso demagógico aspirar a que la alfabetización cambie por sí misma la vida de la gente. 
Es necesario que las políticas públicas se aboquen a generar un panorama que integre oportunidades para acceder al bienestar educativo, económico, laboral, social y cultural. La alfabetización debe mirarse desde sus diferentes aristas, entendiendo que todas ellas son importantes para conseguir equidad y justicia social. Solo así se darán transformaciones profundas en la vida de los ciudadanos. Es imprescindible que priven los intereses comunes, sobre los intereses económicos y políticos de unos pocos.

La precitada autora explica que en el análisis de los resultados de los intentos alfabetizadores, sobresalen criterios mediáticos orientados hacia los datos y las estadísticas. Parecen obviarse en estos casos, aspectos medulares tales como el impacto que puede tener la alfabetización en las condiciones de vida de las personas, en su autoconcepto, en su reafirmación como personas. No se cuestiona, por ejemplo, cuánto han podido avanzar en el sistema educativo quienes han participado de los programas y qué cambios se han generado en sus modos de vida a partir del aprendizaje de la lectura y la escritura. Ubicar esta información solo es posible mediante el seguimiento de los programas antes, durante y después de su aplicación. Es claro, que la concepción política y educativa de la alfabetización como un saber concluido, hace que muchas de estas iniciativas se cierren una vez que se "cumple" con las intervenciones.

Kalman (2008) muestra algunas de las definiciones sobre la alfabetización en países de América Latina (Argentina, Bolivia, Brasil, Colombia, Paraguay y Perú), registradas en el Plan Regional de Alfabetización de la Organización de Estados Iberoamericanos (OEI) para el período 2007-2015. Concluye, que en ellas se le concibe como un proceso escolarizado que involucra la adquisición de habilidades elementales en torno a la lectura y la escritura, además, se le representa como la base del desarrollo social, político y económico.

Justamente, es la visión escolarizada de la alfabetización la que obstaculiza que esta sea vista y atendida como una competencia que sobrepasa los espacios educativos y que, más allá de concebirse como un saber, incluye prácticas letradas diversas que se diseminan en la vida personal, social y profesional de los ciudadanos al formar parte de la cultura, y más específicamente, de la cultura escrita. Castedo (2011) enfatiza que tales prácticas cobran vida fuera de la escuela, haciéndose presentes en los ámbitos de la justicia, el derecho, la familia, la salud, el comercio y los medios de comunicación. Por su parte, Suárez, Vélez y Londoño (2018) adicionan que "Si se sitúa la lectura y la escritura en contextos y motivaciones de uso más amplios, se puede afirmar que los textos que se leen y escriben se insertan en las prácticas de la vida, y no al revés" (p. 187).

Así, se revela cómo la lectura y la escritura se convierten en herramientas para la vida social y laboral del tiempo presente en la multiplicidad de contextos, lenguajes y modos de comunicación e interpretación de la realidad. La autora antes mencionada, agrega que diferentes grupos sociales poseen también distintos modos de apropiación de la cultura escrita, pues no todas las personas leen y escriben con los mismos propósitos, en las mismas modalidades, ni en los mismos ámbitos y momentos. Aunque esto es absolutamente cierto, también lo es el hecho de que las TIC se han convertido en elemento unificador de las prácticas letradas del mundo globalizado. Resulta indiscutible el uso cada vez más acelerado de las redes sociales, los mecanismos de trabajo virtual (teletrabajo), la educación a distancia, la digitalización de la banca, la industria y el comercio. De algún modo, esta nueva dinámica logra aglutinar los intereses y las necesidades de comunicación entre los seres humanos. Desde esta perspectiva, se asume la relación entre la alfabetización y la educación, entendiendo a la primera como una competencia que se inserta dentro de la educación. En líneas posteriores, se prevé poder plantear estas relaciones, a fin de sustentarlas y ponerlas a disposición de los lectores.

\section{La alfabetización como competencia educativa en el mundo actual}

Las condiciones de vida de la actualidad distan en gran medida de lo que significó educarse y vivir en sociedad hasta hace unos veinte o treinta años. Las circunstancias del tiempo presente, caracterizadas por la incertidumbre y la inestabilidad actuando como constantes, exigen una revisión en cuanto 
al concepto de alfabetización para que ajuste a las nuevas formas en las que se vive y representa la realidad.

En su página oficial, la Organización de las Naciones Unidas para la Educación, la Ciencia y la Cultura (UNESCO, 2019) declara que, más allá de la noción habitual que alude al conjunto de competencias en lectura, escritura y cálculo matemático, la alfabetización es concebida hoy día como un modo de identificación, interpretación, comprensión, creación y entendimiento, en un mundo digitalizado, apoyado en textos, basto en información y en rápida evolución. La ampliación del concepto por parte de este importante organismo, confirma lo que se ha dicho en párrafos anteriores: la alfabetización no solo consiste en aprender a descifrar el código alfabético, incluye también habilidades y competencias para el manejo de la información en un mundo caracterizado por cambios y transformaciones globales.

La educación, como proceso que arropa a la alfabetización y que busca el desarrollo del ser humano en todas sus dimensiones y potencialidades, debe estar en la capacidad de dar respuesta a los acelerados cambios tecnológicos y al nacimiento de nuevos recursos que sirven para difundir la información, pero que por sí mismos no generan conocimiento. A juicio de Brunner (2003), la educación debe hacerse cargo de las transformaciones que se dan en el entorno cultural inmediato en el que se desarrollan las tareas formativas, es decir, el contexto de sentidos y significados que faculta a los sistemas educacionales para operar como un medio de transmisión e integración cultural.

Las necesidades formativas que presentan los ciudadanos de hoy para aprender, construir nuevos conocimientos y transferirlos a sus actividades diarias, obligan a que la educación amplíe sus áreas de atención, procurando la superación de la enseñanza de los aspectos mecánicos de la lengua en las iniciativas destinadas a la alfabetización. Es preciso que se pueda aproximar a los ciudadanos al uso autónomo del lenguaje en sus manifestaciones orales y escritas, analógicas y digitales, artísticas y culturales, para asistir al encuentro social provistos de las herramientas de pensamiento que les permitirán su verdadera participación. Sin duda, las necesidades educativas del presente comprometen el empleo de las TIC en sus ventajas y posibilidades. Al respecto, Cabero y Llorente (2008) indican que "En la actualidad la educación en medios de comunicación se va a ver notablemente transformada, entre otros motivos, por la entrada en acción de las denominadas tecnologías digitales" (p. 14).

Un ejemplo que cuenta con absoluta vigencia y que sirve para mostrar cómo se articulan la educación, la alfabetización y las TIC, viene dado por el inesperado asalto a la dinámica mundial producto de la pandemia generada por el virus COVID-19. Este problema de salud ha dejado en evidencia la fragilidad de los sistemas educativos latinoamericanos. También, ha hecho visible la centralidad que tiene cultivar la autonomía del estudiante (ubicado en cualquier nivel de estudio) y la solidez que debe poseer como usuario de recursos tecnológicos y como lector y productor de textos. Estas competencias, le permitirán cumplir efectivamente con sus obligaciones académicas en un contexto de virtualidad, diferente de aquel que se basa en la relación dialógica establecida con el docente en el salón de clases. Dicha situación, merece ser reseñada, pues invoca la reflexión acerca del valor de la lectura y la escritura como saberes transversales que se activan de manera personal y autorregulada ante situaciones de contingencia y distanciamiento social.

A pesar de las desigualdades económicas que arrastran consigo, se debe reconocer que las TIC diversifican las oportunidades para aprender. Así como la Internet permite experiencias de socialización, puede favorecer el encuentro entre docentes y estudiantes de diversos lugares del mundo, la atención individualizada, las tutorías y experiencias pedagógicas en conjunto, la toma de cursos y seminarios a distancia. En interesantes investigaciones en torno al uso de computadores en el aula, la escritura colaborativa en redes y el aprendizaje de segundas lenguas, se discuten los resultados de la aplicación de procedimientos didácticos innovadores basados en recursos multimediales (Estévez, 2012; Franco, 2012; Cassany, 2013; Padrón, 2019).

En síntesis, la tecnología ha trastocado la tradición escolar para ponerla "a tono" con los nuevos tiempos y ha facilitado las relaciones humanas más allá del espacio físico, ofreciendo nuevas propuestas y recursos. Sin embargo, se debe tener conciencia acerca de su uso y acoplamiento, a fin de que el 
estudiante no quede sometido al uso de dispositivos (celulares, tablets, computadoras), sino que ejerza su protagonismo al ser parte activa de este proceso. Entran nuevamente en escena las habilidades de pensamiento crítico, Lipman (1998), y de lectura crítica Cassany (2003) y Fainholc (2005), necesarias para lograr alfabetizarse digitalmente y realizar un procesamiento, lo más consciente posible, de la información con la que se encuentra.

\section{La alfabetización en Venezuela: una mirada a los últimos años}

En el caso concreto de Venezuela, se tiene como experiencia reciente en cuanto al tema de la alfabetización, la Misión Robinson, programa implementado por el gobierno nacional en el año 2003 para alfabetizar a jóvenes, adultos y personas de la tercera edad que por distintas razones no habían aprendido a leer y escribir, a través del método cubano conocido como "Yo sí puedo". Este programa, así como toda la escolaridad en el país, para el período 1999-2010 fueron analizados en un interesante trabajo hecho por Bravo (2011). Su estudio develó que, a pesar de darse una expansión en la atención educativa durante el período examinado, hubo más bien una marcada tendencia al estancamiento y a la contracción, desde la perspectiva de la educación popular. Es importante recordar, que en el año 1999 se comenzó a forjar lo que el gobierno entrante denominó como la "Quinta República", período de cambios drásticos en todas las áreas de la vida nacional.

Los hallazgos del investigador, ponen en tela de juicio las premisas de la inclusión social y educativa, usadas como bandera por el gobierno. En relación con las misiones educativas, Bravo declara que si bien no pueden dejar de reconocerse los propósitos y la voluntad puesta desde el 2003 para incluir a los venezolanos más desfavorecidos en el contexto social de la modernidad, surgen dudas plenamente justificadas al revisar el modo como se calcula la propagación de las misiones educativas, resultando obvio que las cifras referidas a egresados se repiten y abultan los totales que corresponden a cada año. A través de un análisis cuantitativo, el autor concluye que existe una brecha importante entre lo informado por el Ministerio del Poder Popular para la Educación (MPPE) y el aparato de propaganda oficial y lo que se revela en los indicadores de alfabetización que divulga la UNESCO a través de los informes anuales de la Educación para Todos.

Otro importante trabajo de investigación inscrito en la misma línea que el anterior, fue llevado a cabo por Uzcátegui y Bravo (2017). En este, se analiza el tema de la alfabetización en Venezuela en el lapso 1999-2017. La revisión de documentos oficiales (alocuciones presidenciales, informes anuales de Memoria y Cuenta, cálculos publicados por el Instituto Nacional de Estadística y el Ministerio del Poder Popular para la Educación, otrora Ministerio del Poder Popular para la Educación Cultura y Deportes), coincide con lo hallado por Bravo (2011) pues las cifras demuestran una baja en la cantidad de egresados del sistema educativo. Con absoluta razón, los autores argumentan que la merma en el crecimiento del sistema puede alimentar en el futuro la cantidad de población analfabeta. Además, Uzcátegui y Bravo informan que según los resultados del Censo 2011 efectuado por el Institución Nacional de Estadística, el analfabetismo sigue presente en el marco de la realidad pedagógica nacional, lo que desmorona el aclamado milagro educativo sucedido en los últimos veinte años. El 4,92\% de población analfabeta para el 2011 denota un porcentaje superior al número de analfabetos que considera UNESCO en ese mismo lapso y es una proyección cercana al número de analfabetos que registraba el país en el año 1998. A juicio de los investigadores, el censo arroja escasos avances en esta materia, si es que acaso se les puede denominar así.

Es preciso recordar ahora, que el abandono de la escuela y la desatención ciudadana en materia educacional son caldo de cultivo para el analfabetismo. Más allá de las misiones y de la aclamada "revolución educativa", en la actualidad, existe en Venezuela una marcada tendencia hacia la deserción escolar, en los distintos niveles y subsistemas del sistema educativo, por causas que no se exploran del todo, pero que saltan a la vista de cualquier ciudadano que habite en el territorio nacional. Los problemas del venezolano son los mismos: inflación descontrolada, pérdida del poder adquisitivo, precariedad en los servicios públicos, falta de inversión en materia educativa (lo que dificulta el acceso a escuelas de cali- 
dad), abandono sistemático del docente por parte del Estado, desintegración de la familia como núcleo de la sociedad, migración (en auge en los últimos cinco años) y una crisis social y política generalizada.

Albarrán (2019) refiriéndose, de manera específica, a la deserción estudiantil en la Universidad de Los Andes (ULA), encuentra causas sociales y económicas asociadas a este fenómeno: aumento en el costo de la vida, incremento en el precio de los materiales de estudio y demás artículos usados para tal fin, escasez de alimentos, inestabilidad social y pocas ofertas de trabajo. En el aspecto académico, describe las pocas competencias comunicativas, de reflexión y pensamiento crítico, palpables en un débil manejo del razonamiento lógico y de los procesos de la lectura y la escritura. Tales dificultades no acosan solamente a los futuros profesionales, sino que se esparcen de manera dramática en la vida de los estudiantes y sus familias, sin importar el grado o nivel en el que se ubican, razón por la que se convierten en factores determinantes para la exclusión social y educativa.

Todo lo hasta ahora expuesto, debe servir para comprender que el modo como se diseñan los programas oficiales de alfabetización y las políticas educativas en su conjunto, deja al descubierto los ajustes o distorsiones en torno al concepto de alfabetización y el valor que los gobiernos le otorgan a la educación. En este sentido:

Si la alfabetización se concibe como la adquisición de un aprendizaje elemental, basado en la idea de que es un proceso fácil que incluye la habilidad de reconocer desde los sonidos elementales del habla a las grafías sencillas de la escritura, podrán realizarse campañas y acciones que en plazos breves den por superado el problema. Su evaluación, si existe, será muy simple, lo que no sucederá si la alfabetización se considera como un proceso complejo en el que se entrecruzan junto a enfoques educativos, aspectos psicológicos, lingüísticos y culturales. (Infante y Letelier, 2013, p. 17)

De tal manera, que la cobertura real de los esfuerzos alfabetizadores se encuentra vinculada a su consideración como un estado terminado, o por el contrario, como un proceso que se extiende en el tiempo y que supera la promesa y el deber político y educativo. Este último enfoque se inscribe en la perspectiva del aprendizaje permanente desde el que se proyecta a la alfabetización como un aprendizaje a lo largo de la vida. Es allí donde se unen alfabetización y educación, no como dos elementos que tienen afinidad, sino más bien como unidad, como acción integrada que circula a lo largo y ancho del curriculum y de los programas de estudio de todos los niveles de la formación educativa y, también, en la vida ciudadana. Sin duda, que la educación es un motor de cambio y un factor democrático, que debe propender hacia la igualdad de oportunidades y el crecimiento humano

\section{Cultura escrita y alfabetización}

Cuando la alfabetización se convierte en un asunto cardinal para quienes toman decisiones en el campo educativo, los problema derivados del analfabetismo o de las carencias en cuanto a la alfabetización, se resuelven de la mano de la cultura escrita ¿Cómo se puede aspirar a que una persona lea si no tiene acceso a material escrito, ya sea impreso o digitalizado?, ¿cómo se puede pretender tener una sociedad bien educada cuando los libros son exageradamente costosos en comparación con otros artículos, en sí, prescindibles?, ¿es posible formar niños lectores si sus padres y docentes no contagian el amor por los libros? Fomentar la cultura escrita se convierte en un asunto complejo que requiere de sumar voluntades y masificar la lectura y la escritura para que sean accesibles a todos los ciudadanos en todos los contextos socioculturales.

Acciones gubernamentales concretas, tales como inaugurar nuevas bibliotecas, mejorar el acceso a la Internet en los espacios públicos: plazas, parques, terminales de transporte, entre otros lugares, formar a los docentes de los diferentes niveles educativos en torno a la lectura y escritura y dotar a las escuelas de textos novedosos y sobre distintos temas (desde las ciencias hasta la literatura), podrían elevar el nivel educativo en los países de América Latina y en otros territorios del mundo, también desfavorecidos. La organización de ferias y concursos que muestren que leer y escribir son actividades valoradas en el plano social, la reestructuración los espacios de uso común para ofrecer libros y 
otros materiales impresos y la difusión de la información a través de los medios de comunicación (radio, prensa, televisión, páginas web), también contribuirían en la masificación de la cultura escrita.

Vielma (2013) manifiesta que los grupos humanos están regulados por criterios, normas y formas de interactuar mediadas por la lengua y de las cuales se apropian para establecerse como sociedades, como centros creadores y recreadores de la cultura. Es innegable entonces que un entorno social en el que se dignifique a la lectura y la escritura y se les presente como herramientas de poder, conocimiento y libertad, puede ayudar a modificar pautas culturales desfavorecedoras en cuanto a estos procesos, para poder comprender la verdadera significación de la cultura escrita.

Al respecto, Kalman (2008) plantea que la cultura escrita es una práctica social y culturalmente situada, es decir, que viene dada por el uso que se hace de ella en momentos y lugares específicos. En este sentido, coincide con Torres (2008) quien sostiene que el objetivo de alfabetizar "no es enseñar a leer y a escribir a las personas, sino asegurar las condiciones para que lean y escriban efectivamente, significativamente" (p. 2). En torno a la lectura, aunque la idea puede hacerse extensiva a la escritura, Millán (2000) revela que no se trata solo de adquirir algunas técnicas, pues estas de poco servirán si no vienen asistidas por el nacimiento de una motivación. En otras palabras, la formación de lectores y escritores comporta un desarrollo gradual, que demanda tiempo y recursos para afianzar en la práctica aquello que se origina como la esperanza del cambio, como la liberación de un sentido de insuficiencia: el alumbramiento de una nueva vida en la que se lee y se escribe.

Una sociedad alfabetizada puede construirse por medio del trabajo mancomunado de una tríada valiosísima compuesta por familias letradas, comunidades letradas y sociedades letradas. La consolidación de estas tres entidades, aseguraría la solidificación y democratización de la cultura escrita para que pueda ser accesible a todos desde los ámbitos educativos y sociales, generando crecimiento económico y desarrollo humano.

A partir de lo anterior, se reafirma la premisa de que la alfabetización es un aprendizaje que no tiene edad (Torres, 2006). Asumir una visión democrática del conocimiento permite reconocer que se aprende a lo largo de la vida y que la alfabetización inicial abre el camino hacia muchos otros aprendizajes. No es casual que actualmente se hable de alfabetizaciones -en plural- aludiendo así a la alfabetización académica, disciplinar, tecnológica, digital o artística, solo por mencionar algunos tipos. Lo mismo sucede con las culturas escritas, consideradas de esta forma por la amplitud de rasgos lingüísticos, idiomas, géneros, dispositivos tecnológicos e instituciones que reúnen, y que vienen a cambiar las condiciones en las que se despliega la educación.

Se trata, por ende, de un cambio de gran envergadura; en realidad, de concebir y poner en práctica un nuevo modo de producir educación. Más que una preparación para la vida adulta o laboral -un rito de iniciación, la educación pasa a ser, bajo la forma del aprendizaje continuo, la vida misma. Se busca así responder a los grandes desafíos que presentan a la educación los cambios que se están produciendo con la globalización, con la revolución científico-tecnológica, con el uso intensivo del conocimiento en todas las esferas de la actividad humana. (Brunner, 2003, p. 36)

Estos cambios, experimentados ahora mismo en gran escala, ratifican que el aprendizaje ya no puede ser concebido solamente en su dimensión escolar, sino desde el enfoque que lo sitúa a lo largo de la vida. Es entonces una actividad que se prolonga en el tiempo y genera nuevas relaciones y miradas del hecho educativo.

La llamada Sociedad de la Información impone nuevas necesidades de alfabetización relacionadas con la difusión de las tecnologías digitales y los cambios en todos los estamentos de la vida social, Coll (2005). La transformación en los modos de vivir, estudiar y trabajar de los ciudadanos actuales exige que ellos puedan responder con eficiencia a actividades caracterizadas por un uso reiterado de la lectura y escritura como herramientas de conocimiento y poder. 
Para lograr la transformación social y el progreso individual y colectivo, se requiere de políticas integrales que atiendan la alfabetización en conjunto con otros aspectos sociales y económicos como el acceso al trabajo, a la tecnología, el derecho a la educación, la vivienda, la salud, la alimentación, la cultura, la recreación y al disfrute de servicios públicos de calidad. La Agenda 2030 para el Desarrollo Sostenible, aprobada por la UNESCO hace ya cinco años, contempla diecisiete objetivos que abordan diferentes áreas del desarrollo humano.

El objetivo número 1 titulado "Poner fin a la pobreza en todas sus formas en todo el mundo" resalta que, desgraciadamente, el $10 \%$ de la población mundial, continúa viviendo en situación de pobreza extrema, con problemas para satisfacer necesidades básicas relativas a la salud, la educación, el acceso a agua y el saneamiento ambiental. Por esta razón, se ratifica el compromiso del organismo para brindar atención a las poblaciones que más lo necesitan y garantizar la protección social de los niños y otros grupos vulnerables como factores claves para reducir la pobreza.

Por su parte, el objetivo número 4 denominado "Garantizar una educación inclusiva, equitativa y de calidad y promover oportunidades de aprendizaje durante toda la vida para todos", reitera que la educación posibilita la movilidad social y económica en dirección ascendente, por lo que resulta clave para superar la pobreza. Sin embargo, en la descripción de este objetivo se plantea que cerca de 260 millones de niños estaban fuera de la escuela en el 2018. Además, más de la mitad de todos los niños y adolescentes del mundo entero no están logrando los estándares mínimos de competencia en lectura y matemáticas. En marzo de 2020 la institución conformó una Coalición Mundial para la Educación COVID-19, con el propósito de ayudar a los países a abordar los desfases tecnológicos, y a ofrecer oportunidades de aprendizaje inclusivo para niños y jóvenes durante este lapso de alteración educativa.

La voluntad de cooperación debe ser un signo del tiempo presente en todas las redes de interacción humana, desde la base que conforman las familias, pasando luego por las instituciones educativas, hasta llegar a las autoridades que rigen los destinos de las naciones y a los organismos multilaterales. Sin duda, el contexto global de la emergencia sanitaria, ha visibilizado la educación, con sus fallas y posibilidades, convirtiéndola en una cuestión de interés colectivo. El interés y apoyo en las TIC para que los procesos formativos sigan su curso, es irrefutable. Cassany (2013), considera que las iniciativas en TIC y TAC (Tecnologías del Aprendizaje y el Conocimiento) son una oportunidad inmejorable para efectuar un salto cualitativo en educación y no quedar desmontados.

Como fenómeno educativo, la alfabetización también debe acoplarse a las circunstancias del tiempo presente. Resulta obvio que no es un momento oportuno para ejecutar trabajos de campo, pero lo que sí puede promoverse es la cultura escrita en el seno del hogar, a través de las bibliotecas digitales, de los medios de comunicación y por medio de eventos académicos y culturales que tienen cabida en el mundo de la virtualidad. Torres (2006) manifiesta que "en sociedades democráticas o que aspiran a ser democráticas, el servicio educativo requiere abrirse, flexibilizarse y diversificarse a fin de satisfacer las necesidades básicas de aprendizaje de la población a cualquier edad, dentro y fuera del sistema escolar" (p. 4).

La alfabetización y la educación son procesos indisolubles, por lo que ocuparse de este binomio solo debería corresponderle a quienes verdaderamente se preocupan por el futuro de la humanidad y apuestan a los valores ciudadanos. Kalman (2008), expresa que el aprendizaje de la lectura y la escritura es un asunto de conexión humana, que está sujeto a otros lectores y escritores. Así, el conocimiento sobre los múltiples usos de la lengua escrita surge de las oportunidades que se tengan para participar en situaciones comunicativas que requieren de la cultura escrita. Tal y como lo plantea Castedo (2011) "La cultura escrita no es, se va haciendo y es nuestra aspiración que todos tengamos derecho a ser parte de la obra" (p. 23). Lograr esta participación es posible solo si se parte de preceptos como la libertad, la democracia y la inclusión social, entretejidos en una acción educativa que supera a la escuela y sus valiosas posibilidades, para extenderse a otros contextos de participación y a los medios que procuran la presencia de la lengua escrita en toda su riqueza y diversidad. 
Para finalizar, es importante destacar que las dificultades en el acceso a la cultura escrita y los problemas asociados a la alfabetización en Latinoamérica y en otros lugares del mundo, deben conducir a que cada actor social asuma su responsabilidad. La familia tiene un papel fundamental en la educación de los hijos, en su desarrollo afectivo y emocional, en su formación académica y social. La escuela ejerce también un rol cardinal en la promoción de la cultura escrita más allá de la reproducción y del afán por el desarrollo de los contenidos programáticos. Los gobiernos, por su parte, adquieren un compromiso con la ciudadanía al sentar las bases y facilitar las condiciones para que la alfabetización y la cultura escrita se inserten en el marco del encuentro social de modo natural y constructivo.

\section{Referencias}

Águila, E. (2019). Formación en ciudadanía, pedagogía de la experiencia y experiencias críticas en educación. Educar para la ciudadanía: fundamentos, metodologías y desarrollo profesional docente (pp. 65-77). Saberes Docentes. Centro de Estudios y Desarrollo de Educación Continua para el Magisterio de la Universidad de Chile. https://n9.cl/1ut6

Albarrán, J. (2019). La deserción estudiantil en la Universidad de Los Andes (Venezuela). Revista Educación y Humanismo, 21(36), 60-92. http://dx10.17081/eduhum.21.36.2806

Brunner, J. (2003). Educación al encuentro de las nuevas tecnologías. En J. Tedesco y J. Brunner (Eds.), Las nuevas tecnologías y el futuro de la educación. Septiembre Grupo Editor. https://n9.cl/v9md

Bravo, L. (2011). 12 años de educación en Venezuela (Escolaridad y alfabetización 1999-2010). Escuela de Educación, Universidad Central de Venezuela. https://n9.cl/qvtu

Cassany, D. (2003). Aproximaciones de la lectura crítica: teoría, ejemplos y reflexiones. Tarbiya. Revista de investigación e innovación educativa, 32, 113-132. https://n9.cl/26p6q

Cassany, D. (2013). ¿Cómo se lee y se escribe en línea? Revista electrónica Leer, Escribir y Descubrir, 1(1), 01-24. https://n9.cl/qi9y

Coll, C. (2005). Lectura y alfabetismo en la sociedad de la información. UOC Papers, (1), 4-10. https:// n9.cl/emzk

Cabero, J. y Llorente, M. (2008). La alfabetización digital de los alumnos. Competencias digitales para el siglo XXI. Revista Portuguesa de Pedagogía, 42(2), 7-28. https://n9.cl/zow3b

Castedo, M. (2011). Formación de docentes en el área de lectura y escritura. Cuadernos REDPLANES. La formación de mediadores en el contexto educativo (pp. 21-29). CERLALC-UNESCO. https:// n9. cl/2o20

Estévez, M. (2012). Análisis y beneficios de la incorporación de las TIC en el área de Lengua Castellana y Literatura: un caso práctico. Píxel-Bit, Revista de Medios y Educación, 40, 21-34. https://n9.cl/ kvh6

Fainholc, B. (2005). La lectura crítica en Internet. Lectura y Vida, 26(2), 34-41. https://n9.cl/8ohs

Franco, V. (2012). "Trabajamos juntos": un espacio de escritura colaborativa para el alumnado inmigrante. RedELE revista electrónica de didáctica del español lengua extranjera, (24), 1-26. https:// n9.cl/e535w

Flores, L. y Sánchez, M. (2013). Alfabetización de niños, niñas y personas adultas: componente indispensable en la formación docente. Revista Electrónica Leer, Escribir y Descubrir, 1(1), 25-41. https://n9.cl/8021e

Infante, M. y Letelier, M. (2013). Alfabetización y Educación. Lecciones desde la práctica innovadora en América Latina y el Caribe. Oficina Regional de Educación para América Latina y el Caribe/ UNESCO. https://n9.cl/i6z8

Kalman, J. (2008). Discusiones conceptuales en el campo de la cultura escrita. Revista Iberoamericana de Educación, (46), 107-134. https://n9.cl/z52x

Lipman, M. (1998). Pensamiento crítico y educación. Ediciones de la Torre. 
Lipman, M. (2016). El lugar del pensamiento en la educación. Octaedro.

Millán, J. (2000). La lectura y la sociedad del conocimiento. Federación de Gremios de Editores de España. https://url2.cl/LWyry

Padrón, T. (2019). Desarrollo de las capacidades lingüísticas y culturales de estudiantes de un liceo en Francia mediante la interacción con hablantes nativos (trabajo final de pregrado). Universidad de Los Andes, Mérida, Venezuela.

Suárez, P., Vélez, M. y Londoño, A. (2018). Las herramientas y recursos digitales para mejorar los niveles de literacidad y el rendimiento académico de los estudiantes de primaria. Revista Virtual Universidad Católica del Norte, 54, 184-198. https://n9.cl/crfg

Torres, R. (2006). Alfabetización y aprendizaje a lo largo de toda la vida. Revista Interamericana de Educación de Adultos, 28(1) 25-38. https://n9.cl/cpgl

Torres, R. (2008). "No basta con enseñar a leer y a escribir; hay que acercar la lectura y la escritura a la gente". UNI-PLURI/UNIVERSIDAD, 8(1), 1-7. https://n9.cl/o0kgw

Uzcátegui, R. y Bravo, L. (2017). La alfabetización en Venezuela según la perspectiva y las cifras de Memoria Educativa. TrasHs Trayectorias Humanas Trascontinentales (2), 32-49. https://n9.cl/8aje

Vielma, J. (2013). La cultura y su impacto en el quehacer profesional: un ejercicio introspectivo. Entre Lenguas, 18(23), 37-44. https://cutt.ly/4dtknx8

Vielma, J. (2016). El cuento: una posibilidad para la mediación de la lectura en el aula. Legenda, 20(23), 207-222. https://url2.cl/8m9Ka

Organización de las Naciones Unidas para la Educación, la Ciencia y la Cultura (2019). Alfabetización. https://n9.cl/dvs3

Organización de las Naciones Unidas para la Educación, la Ciencia y la Cultura (2020). 17 objetivos para transformar nuestro mundo. https://n9.cl/k7kp 